\title{
Explorative study on Compressed Air Systems' energy efficiency in production and use: first steps towards the creation of a benchmarking system for large and energy-intensive industrial firms ${ }^{1}$
}

\author{
Miriam Benedetti ${ }^{* a}$, Francesca Bonfa' ${ }^{b}$, Ilaria Bertini ${ }^{b}$, Vito Introna $^{c}$, Stefano Ubertini ${ }^{\mathrm{d}}$ \\ ${ }^{a}$ Institute for Manufacturing, University of Cambridge, Cambridge, CB, UK \\ ${ }^{\mathrm{b}}$ Energy, New Technology and Environment Agency (ENEA), Rome, RM, Italy \\ 'Department of Enterprise Engineering, “Tor Vergata” University of Rome, Rome, RM, Italy \\ ${ }^{\mathrm{d}}$ Department of Economics, Engineering, Society and Business Organization (DEIM), University of Tuscia, Viterbo, VT, Italy \\ *Corresponding author: mb2132@cam.ac.uk
}

\begin{abstract}
${ }^{1}$ The short version of the paper was presented at ICAE2016 on Oct 8-11, Beijing, China. This paper is a substantial extension of the short version of the conference paper.

ABSTRACT

Compressed Air Systems (CAS) are one of the most common and energy intensive utilities in industry, representing up to $10 \%$ of the industrial energy needs. Thus, they can be considered as one of the main target systems while planning energy efficiency actions implementation in industry. Nevertheless, most of the available benchmarks of energy consumption are based on nominal data, thus referringto the quality of the design, while benchmarks based on measurements under actual operating conditions are not yet available.

In accordance with the Italian transposition of the European Directive 2012/27/EU (i.e. Legislative Decree 102/2014), large and energyintensive business organizations must perform energy audits at least every four years starting in 2015 and the Italian Energy, New Technology and Environment Agency (ENEA) has the task of collecting and analyzing them. In this context, adata collection focused on CAS has been carried out and the subsequent data analysis, focused on nine most promising industrial sectors, has allowed to assess the current state of the art of CAS's energy efficiency in Italy and to design a possible benchmarking system. Such a system iscomposed of a set of indicators and a benchmarking visual tool in the form of a matrix. In particular, results related to the Manufacturing of basic metals will be presented for sake of brevity. In this paper we present the results obtained from both the data analysis and the first application of the proposed benchmarking system, together with next steps for the creation of reliable sectorial and cross-sectorial benchmarks.
\end{abstract}

Keywords: Energy Efficiency, Compressed Air Systems, Directive 2012/27/EU, energy benchmarking. 


\section{Introduction}

The increasing worries concerning the scarceness of energy resources and climate change are forcing the global community to face new challenges and to revolutionize the way energy is produced and consumed all over the world. The European Union in particular is currently trying to undertake several actions aimed at decreasing the dependency on energy imports, reducing greenhouse gas emissions and overcoming the economic crisis. To fulfil all of these arduous tasks, energy efficiency is an extremely valuable means, as it improves the security of supply by reducing primary energy consumption and the greenhouse gas emissions (and thereby mitigates climate change), and allowing to decrease energy imports in a cost-effective way [1-4]. In particular, energy efficiency analysis has become an important topic in various disciplines such as energy economics and operations research. The aim of energy efficiency analysis is to evaluate a decision making unit's efficiency in terms of energy input by comparing its energy consumption to its peers in a similar production environment, which in turn leads to possible actions for energy efficiency improvement and provides analysis foundation for energy and environmental decision making [5].

In this context, aiming at reducing energy wastes, to have a precise understanding of CAS's electrical and primary energy consumption is of utmost importance given their relevance, from an energy point of view, in most industrial systems Thus, the European Directive 2012/27/EU [1] is a starting point for further energy efficiency improvement actions in industrial companies and CAS are certainly one of the main priorities. With the promulgation of such Directive, the European Union (EU) has established a common framework of measures for the promotion of energy efficiency in order to ensure the achievement of the EU's energy efficiency improvement target of a $20 \%$ reduction of current primary energy consumption by 2020 , and to pave the way for further energy efficiency improvements beyond that date. In this context, CAS play a strategic role in order to achieve the always more compelling objective of reducing industrial energy consumption in Europe as well as in the rest of the world $[6,7]$, due to their large diffusion in industrial plants [8] and to their energy intensity [8-11]. Italy has transposed the cited Directive into national law by issuing the Legislative (Lgs.) Decree ${ }^{\circ} 102$ of the 4 th July 2014 [12]. According to Art. 8 of such Decree, the large [13] and energy intensive (i.e. enlisted in the ad hoc list for the electricity sector of Cassa Conguaglio) enterprises must undergo energy audits on their plants at least every four years, starting from the deadline that was 5 December 2015.

The implementation of the Lgs. Decree 102/2014 in 2015 has been the perfect opportunity to gather CAS-related data in order to assess the current energy efficiency level of compressed air production and use in the Italian industry, to define effective benchmarks and to enhance knowledge and best practices transfer among undertakings. These activities will contribute to the increment of CAS's energy efficiency. In such context, the Italian Energy, New Technology and Environment Agency (ENEA, “Agenzia nazionale per le nuove tecnologie, l'energia e lo sviluppo economico sostenibile"), in collaboration with the University of Rome "Tor Vergata" and the University of Tuscia, has set up a series of studies aimed at helping companies in the difficult job of assessing, benchmarking and improving their energy efficiency, and at providing them with accessible, easy and effective tools.

Data gathered were not limited to CAS, but preliminary analyses were conducted on these systems due to their relevance from an energy efficiency point of view, as previously highlighted. As a matter of fact, only a few relevant and reliable benchmarks are available in scientific and technical literature, as for example [8, 14-16], but they are usually referred only to the production phase and are generally 
calculated in nominal conditions, not considering system's deterioration over time, specific operating conditions and also the influence of set points and demand fluctuations. This makes such information very unhandy and often confusing for companies. In such context, a series of studies has been set up aimed at helping companies in assessing, benchmarking and improving CAS's energy efficiency, and at providing them with accessible, easy and effective tools.

The use of Italian data is only due to the availability given by the application of the cited Decree, and should not be considered as a limitation for the applicability of main findings and results. In fact, data have been used to design the benchmarking methodology and tools presented in this paper, and while the validity of numerical results in different contexts shall be further tested, the methodology and tools can be applied to an international context. The application of the methodology and tools to different contexts will on the one hand further inform this design phase and on the other hand help provide support to the evaluation of energy efficiency of high energy-consuming industries, which is always more playing an important role in different countries [17].

In the followings, main literature regarding energy consumption benchmarking in industry, as well as CAS's energy efficiency and benchmarking will be recalled. After that, the methodology used to create benchmarks for CAS's energy efficiency in industry (from data collection to the creation of visualisation tools) is presented, together with main results obtained by applying it to the It alian context (and to the Manufacture of basic metals in particular). Results will be then discussed and main conclusions will be presented, together with some consideration regarding their general applicability.

\subsection{Energy consumption benchmarking in industry}

Benchmarking has been recognized to be an effective analysis methodology and management tool that helps to improve efficiency and performance in many areas for different objectives $[18,19]$ and has been well described in literature [20-23]. Energy benchmarking is defined as a process of measuring energy performance of an individual plant or sector against a common metric that represents "standard" or "optimal" performance of that plant or sector [18]. Benchmarking can also be designed to compare the energy performance of a number of plants against one another or to compare the plant against itself in different time periods or under different operating conditions [18]. It is therefore useful for understanding energy use patterns, identifying inefficiencies in energy use, estimating the potential for energy conservation, and designing policies to improve energy economy [24].

Several reviews have been published on energy benchmarking methodologies in different fields. Chung [20] compared mathematical models for energy benchmarking in buildings, while Li et al. [25] focused on differences between black, grey and white box methods. Always considering buildings as main unit of analysis, Zhao and Magoules [26] reviewed the modelling and prediction of energy consumption, considering engineering, statistical and artificial intelligence methodologies, while Perez-Lombardi [27] analysed concepts such as energy ratings and labelling. Ahn et al. [28] proposed a review as well as a new statistical method to benchmark energy intensity of subway stations. Finally, while previous cited works generally refer to the benchmarking of energy performance of an entire site (or sector), Longo et al. [29] present a review of existing energy consumption benchmarking methods and tools for wastewater treatment plants, while Kalaiselvan et al. [30] and and Mui et al. [31] focus on centrifugal pumping systems and ventilation systems, respectively. These are rare examples of benchmarking methodologies and tools proposed for specific technical systems. In fact, although this is not acommon practice, 
focusing on a specific system allows taking into account operations issues and efficiency improvement and gives more significant and reliable results. Benchmarking similar equipment is one method of identifying poor performing systems and estimating improvement potential. Actions for performance improvements can then be developed, prioritized and implemented based on benchmarking results [32].

Most benchmarking exercises are based on statistical analysis of time series and cross sectional data [33]. Statistical methods focus on the comparison of SEC amongst existing plants. This method involves data collection, analysis and reporting of the operational data. Statistical benchmarking is widely used (see following Table, adapted from [34]), and its main limitation is that the variations due to operating conditions of the processes are not considered and only similar plants or processes can be compared [34]. Researchers usually try to overcome such limitation by model based benchmarking, which generally results difficult to apply and not user-friendly for practitioners. This paper presents an alternative approach for considering operating conditions and systems with different size, with a relatively simple statistical approach.

Table 1. Examples of different benchmarking model types and methods applied to different context (table adapted from [34])

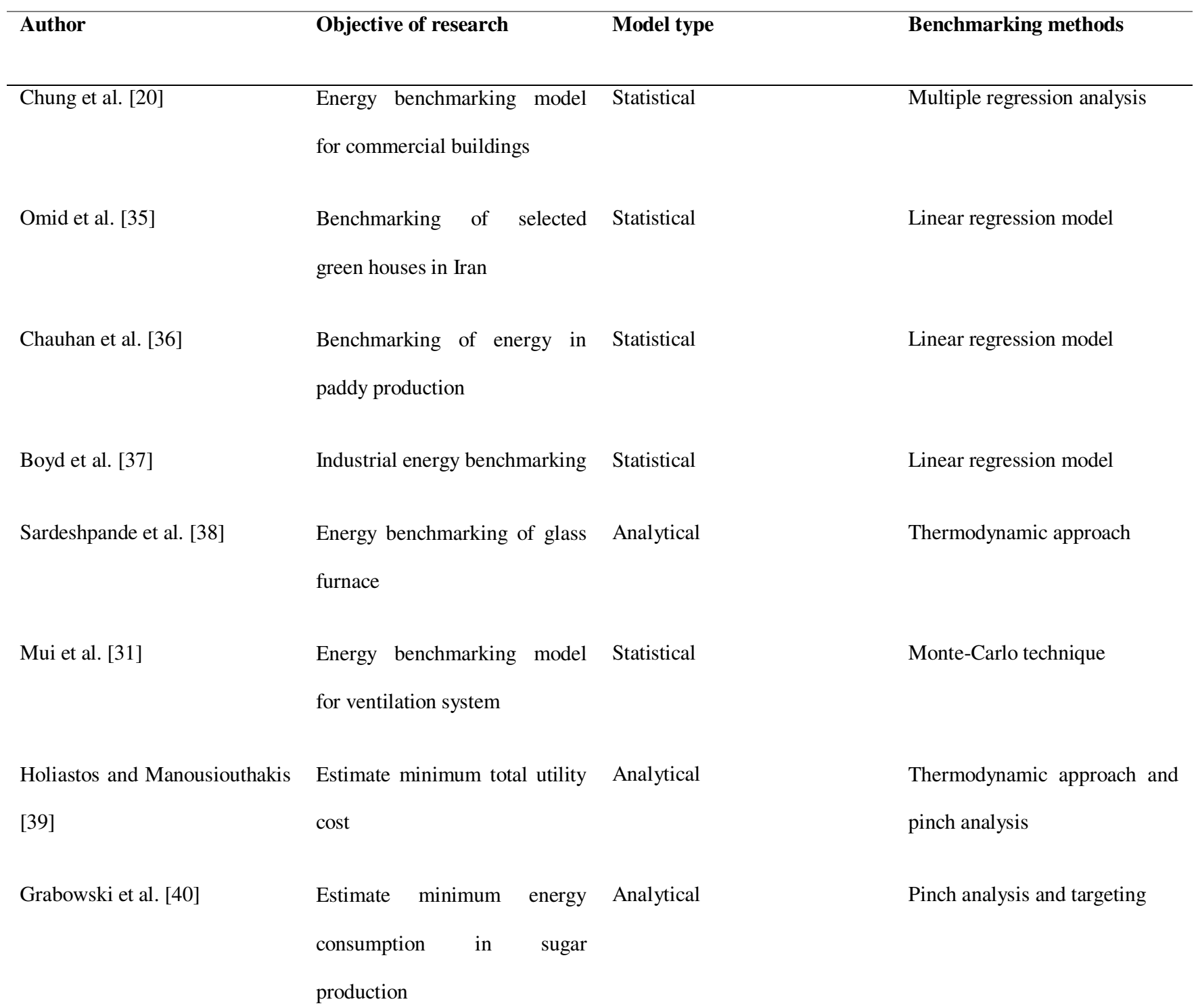

production 
To the best of the authors' knowledge, there are no standard approaches to evaluate CAS energy performance. In this paper, authors describe the challenges inherent to CAS energy benchmarking and give an overview of efforts made by both academics and practitioners to improve their energy efficiency. Authors have used some methods that are widely adopted for benchmarking, as they have proved to be effective, but some features have been added in order to ease results' visualisation and to take differences among analysed systems into account, making the methodology more dynamic and widely applicable. This paper represents therefore a first step in the development of a systematic methodology for evaluation and improvement of energy performance in CAS operation.

\subsection{Compressed Air Systems energy efficiency and benchmarking in industry}

CASs are extremely common in industrial plants [8, 41-46], asthey are employed in approximately $70 \%$ of Italian industrial plants [8]. Compressed air is, in fact, characterised by a good transportability, safety, purity and storability and can be used as an energy carrier for various processes, like drilling, carving or energy storage, or as a process fluid carrier, for example in cleaning or varnishing) [42, 47]. In addition, they represent a huge percentage of the total industrial energy consumption in most industrialized countries [8], and the improvement of their efficiency is therefore a strategic goal. In fact, the energy cost of this utility is one of the highest in industry, as air has to be treated in various ways, filtered, compressed and refrigerated before being stored, transported and finally used as energy vector. Nevertheless, still little attention is paid across most manufacturing and process industries to this topic, and, as a result, most industrial CAS are poorly designed, with an emphasis on risk aversion rather than actual operational efficiency. In most cases this resu lts in oversized systems, with spare installed capacity to insure against such losses, which typically compromises the long-term energy efficiency of the installation [43]. Potential savings due to the improvement of CAS energy efficiency are estimated to be around 20-30\% of current energy consumption [43].

Radgen and Blaustein [8] estimated the energy consumed to produce compressed air in Europe to be about the $10 \%$ of the total industrial energy consumption (and up to 70\% for particular industries according to [9]), and such value was later confirmed by other authors in other contexts [44-46]. The high energy intensity of these systems is mainly due to the fact that only the 19\% (or less [48]) of the energy employed to produce compressed air is actually available to final users [49].

For all of these reasons CASs can be considered the most expensive of all the most common industrial utilities from an energy point of view (their energy cost represents up to the $73 \%$ of their lifecycle cost calculated over ten years), which is the reason why monitoring and improving their energy efficiency is of utmost importance [50].

Given their strategic importance, there are several papers [8-11,15,51-53] and whitepapers [16,50,54-59] in literature reviewing best practices, techniques and technologies allowing CASs to be as energy efficient as possible. In order to give a brief and general overview of most common energy efficiency best practices applied to CAS, a detailed list is reported in the Figure 1, together with the recommendation rate (blue bars), the estimated payback (in brackets) and energy saving (green bars) for each practice. 


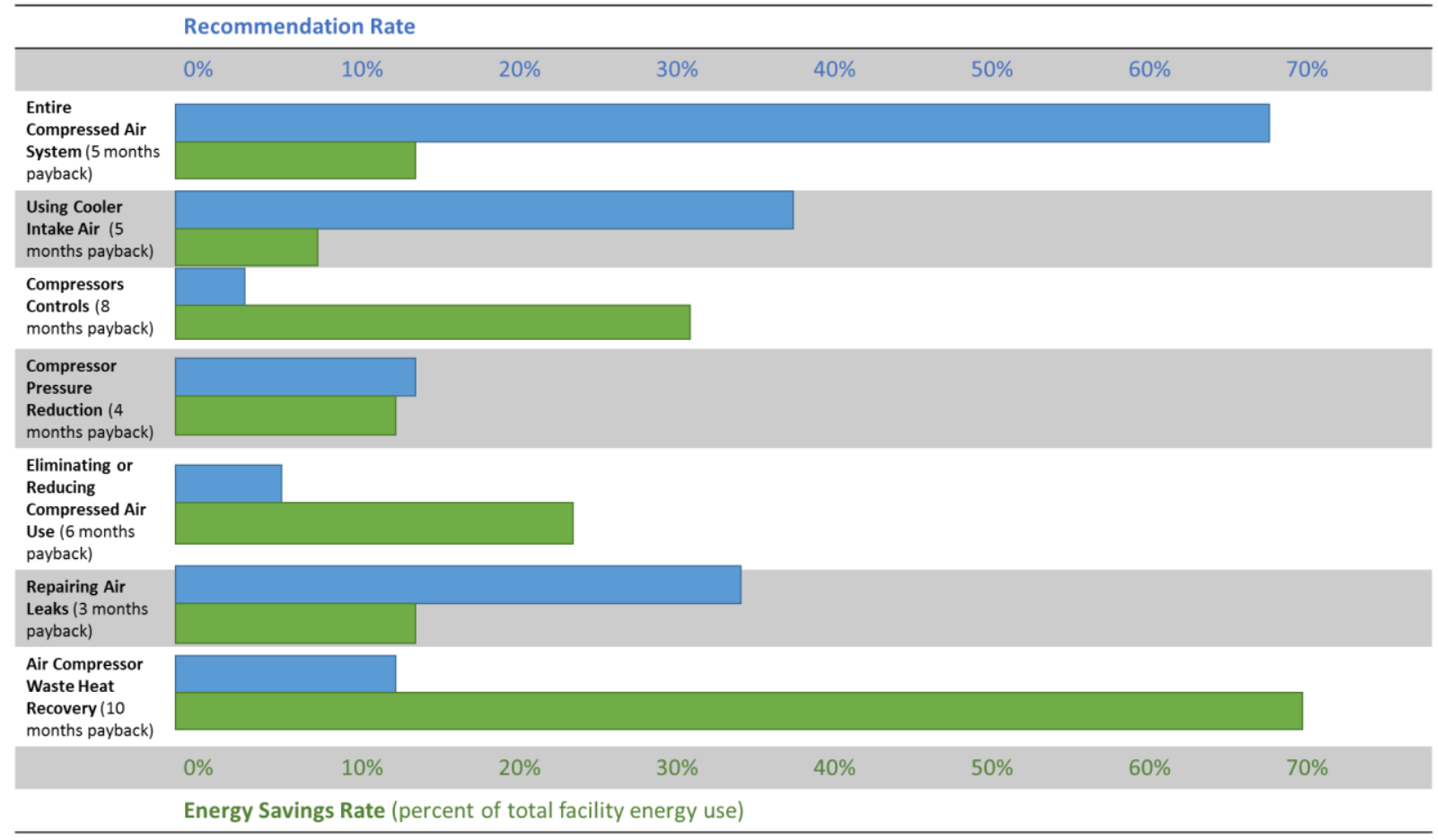

Fig. 1. Energy saving and payback period for different improvement actions in Air Compressors systems (adapted from [60])

Despite this, only a few benchmarks are given which can be considered relevant and reliable, as for example [8,14-16].

In particular, Radgen and Blaustein [8] mainly mention benchmarks in the context of the definition of a European energy label for air compressors, with the aim of enhancing efficient machines' adoption within industry. Therefore, it is referred to benchmarking performances in standard or nominal condition. In addition, they focus on the design phase and on the air compression equipment only, excluding downstream issues, such as distribution networks, overall system design or leak detection. Authors envisage the necessity of defining some sort of categorisation of systems for benchmarking purposes, mainly based on air quality and nature of variable loads, thus once again considering only design information.

The European commission prepared a document [14] for benchmarking the efficiency of energy consuming systems in business organizations. Such a document includes a description of the main technical systems, together with a list of main common energy saving opportunities for each of them. In the economics section of the CAS discussion, the benchmark value for the specific energy consumption is given for a correctly dimensioned and well managed installation, operating at a nominal flow and at a pressure of 7 bars: according to authors, it should be within 85 and $130 \mathrm{Wh} / \mathrm{Nm}^{3}$. In this case, as opposed to what stated for the previous reference, this value takes into account the operation of the whole system, not only of the air compression phase, but it still refers to nominal conditions.

Anglani and Mura [15] performed an energy audit campaign where CAS belonging to different companies from various industrial sectors had been analysed from an energy efficiency point of view. In their report, differences in the efficiency of the use phase of compressed air are highlighted, leading to the conclusion that benchmark values should be defined per each industrial sector. In addition, a uthors conclude that benchmarks should be based on measured data rather than on nominal data in order to be more effective and to allow companies to use them also in the use phase. However, the data set used in this report is limited and the authors could not propose a final benchmark value. 
Finally, also the U.S. Department of Energy [16] proposes a data based approach to benchmarking, and details a list of required measures: electric power, pressure, flow rate and temperature under different operating conditions, as well as the estimating leak load. By doing so, authors basically state that benchmarking is needed in CAS use phase, in order to establish current performance levels and costs of a CAS, and to correlate the results to the specific plant's production level.

This is the first study, to the best of authors' knowledge, based on such a large data collection and is the first step to the definition of a unique set of benchmarks which will help business organizations to assess their energy efficiency in the production and use of compressed air, so as to guide them in the correct implementation of existing best practices.

\section{Methodology}

\subsection{Target}

The target of this study are large and energy intensive enterprises operating in Italy and has been set on the basis of the Legislative Decree 102/2014, which motivated the study itself. The data collection process has been applied to the whole target. In addition, it has been considered that energy efficiency of high energy-consuming industries plays a significant role in social sustainability, economic performance and environmental protection of any nation [17]. As too many undertakings qualified for the cited Legislative Decree, data analyses have been initially limited to nine industrial sectors, selected for their intensive use of compressed air on the basis of existing literature $[15,16]$.

The following nine sectors (defined according to the 2007 NACE, the Statistical classification of economic activities in the European Community [61]) are considered in this study.

- Manufacture of basic metals: this sector includes the activities of smelting and/or refining ferrous and non-ferrous metals from ore, pig or scrap, using electrometallurgy and other process metallurgic techniques it also includes the manufacture of metal alloys and super-alloys by introducing other chemical elements to pure metals: the output of smelting and refining, usually in ingot form, is used in rolling, drawing and extruding operations to make products such as plate, sheet, strip, bars, rods, wire or tubes, pipes and hollow profiles, and in molten form to make castings and other basic metal products.

- Manufacture of chemicals and chemical products: this sector includes the transformation of organic and inorganic raw materials by a chemical process and the formation of products; it distinguishes the production of basic chemicals that constitute the first industry group from the production of intermediate and end products produced by further processing of basic chemicals that make up the remaining industry classes.

- Manufacture of basic pharmaceutical products and pharmaceutical preparations: this sector includes the manufacture of basic pharmaceutical products and pharmaceutical preparations; it also includes the manufacture of medicinal chemical and botanical products.

- Manufacture of fabricated metal products except machinery and equipment: this sector includes the manufacture of "pure" metal products (such as parts, containers and structures), usually with a static, immovable function; the manufacture of weapons and ammunition is also included in this division. 
- Manufacture of motor vehicles: this sector includes the manufacture of motor vehicles for transporting passengers or freight; the manufacture of various parts and accessories, as well as the manufacture of trailers and semi-trailers, is included here.

- Manufacture of plastics products: this sector comprises processing new or spent (i.e. recycled) plastics resins into intermediate or final products, using such processes as compression moulding, extrusion moulding, injection moulding, blow moulding, and casting; for most of these, the production process is such that a wide variety of products can be made.

- Manufacture of textiles: this sector includes preparation and spinning of textile fibres as well as textile weaving, finishing of textiles and wearing apparel, manufacture of made-up textile articles, except apparel (e.g. household linen, blankets, rugs, cordage etc.).

- Manufacture of food products: this sector includes the processing of the products of agriculture, forestry and fishing into food for humans or animals, and includes the production of various intermediate products that are not directly food products; it includes activities dealing with different kinds of products: meat, fish, fruit and vegetables, fats and oils, milk products, grain mill products, animal feeds and other food products.

- Manufacture of paper and paper products: this sector includes the manufacture of pulp, paper and converted paper products. The manufacture of these products is grouped together because they constitute a series of vertically connected processes; more than one activity is often carried out in a single unit, of essentially three types: the manufacture of pulp involves separating the cellulose fibres from other matter in wood, or dissolving and de-inking of used paper, and mixing in small amounts of reagents to reinforce the binding of the fibres; the manufacture of paper involves releasing pulp onto a moving wire mesh so as to form a continuous sheet; converted paper products are made from paper and other materials by various techniques. The paper articles may be printed (e.g. wallpaper, gift wrap etc.), as long as the printing of information is not the main purpose.

\subsection{Data Collection Process}

The exploratory study has been undertaken simultaneously with the implementation of the Legislative Decree 102/2014, in order to obtain the largest possible visibility and diffusion amongst target enterprises. Target organisations have been asked to complete a voluntary semistructured questionnaire in the form of a spreadsheet, and to submit it together with the mandatory documentation. The questions asked in the spreadsheet are summarized in Table 2. The collected variables (summarized in Table 3) are production volumes, total electrical consumption, indicated as kWhe TOT, amount of energy consumed for the production of compressed air, indicated as kWhe CAS, and value of the main energy driver. Both questions and variables are referred to the year 2014.. Submissions started in October 2015 and closed on December 2016. Given the exploratory nature of this study, no power analysis and sample size calculation was performed in a preliminary fashion.

Table 2. Questions and percent breakdown of responses

\begin{tabular}{ll}
\hline Questions & Possible answers \\
\hline Methodology adopted for estimating total electrical consumption & Calculated from energy bills \\
& Spot measures \\
& Continuous measures provided by dedicated meters \\
Undeclared
\end{tabular}


Methodology adopted for estimating the energy consumed for the production of compressed air

Please indicate the main energy driver you use to evaluate the performance of your
compressed air system
Methodology adopted for estimating values related to the main energy driver for your
compressed air system
compressed air system
Calculated from energy bills

Spot measures

Continuous measures provided by dedicated meters

Undeclared

Compressed air production

Others

Undeclared

Calculated on the basis of nominal system's parameters or of physics

Spot measures

Continuous measures provided by dedicated meters

Undeclared

Table 3. Variables collected in the spreadsheet

\begin{tabular}{ll}
\hline Variables & Unit of measure \\
\hline Production volumes & Not standardized \\
Total electrical consumption (kWheTOT) & {$[\mathrm{kWh}]$} \\
Amount of energy consumed for the production of compressed air (kWhe CAS) & {$[\mathrm{kWh}]$} \\
Value of the main energy driver & Not standardized \\
\hline
\end{tabular}

\subsection{Data preparation for analysis}

In order to make the data analysis process easier and more effective, data have been previously prepared as follows:

- $\quad$ questionnaires returned by the same enterprise for different plants have been identified, separated and named with different IDs so as to be analysed as separate entities;

- $\quad$ production volumes have been all converted in tons if expressed in a weight unit of measure;

- energy driver's measures have been all converted in $\mathrm{m}^{3}$, if the energy driver indicated was the amount of compressed air produced;

- $\quad$ derived variables have been calculated.

The data analysis is performed on the following derived variables:

- the ratio between the amount of energy consumed for the production of compressed air and the total electrical consumption (kWhe CAS/kWheTOT);

- the ratio between the amount of energy consumed for the production of compressed air and the production volumes (kWhe CAS/t) $[17,32,34,62]$

- the ratio between the amount of energy consumed for the production of compressed air and the value of the main energy driver $\left(\mathrm{kWhe} \mathrm{CAS} / \mathrm{m}^{3}\right)$.

The choice of the last variable is due to the fact that the amount of compressed air is the most used energy diver in the questionnaires, and also coherent with results presented in [19].

The analyses presented in the present paper refers on a part of the submitted questionnaires (i.e. those submitted electronically). 


\subsection{Data Analysis}

The data analysis has been performed in different steps, using different statistical analysis tools. The distribution of the collected variables has been first analysed and its normality has been assessed with the Anderson-Darling test [63]. Then, variables have been examined by calculating descriptive statistics (frequencies, percentages, averages, medians, standard deviation and confidence of intervals at $95 \%$ ). To compare industries' sub-sectors, the Welch's One-Way ANOVA [64] test has been used to evaluate differences in the means of continuous variables. This test has been selected for its wide applicability, as it does not assume data sets to be normally distributed if they have an adequate size or to have similar standard deviations. Statistical tests have been performed accepting a probability value $(\mathrm{P}$-value $) \leq 0.05$. Such analyses have been performed for each industry and also repeated for industries' subgroups limited to those that have provided continuously measured data, except for the Welch's One-Way ANOVA test due to the restricted samples size. Analyses regarding the $\mathrm{kWhe} \mathrm{CAS} / \mathrm{m} 3$ derived variable have only been conducted on subgroups, as non-measured data seemed useless in this case, and crosssectorially, in order to avoid problems due to restricted sample size.

A benchmarking tool is proposed and a benchmarking analysis is also performed for each industry and for each subsector. The benchmarking analysis is based on the evaluation of two variables: the amount of energy consumed for the production of compressed air and the Efficiency Ratio, defined as the ratio between the actual amount of energy consumed for the production of compressed air and the amount of energy that should have been consumed according to the baseline (see following Equation).

$E R=\frac{k W h_{e} A C_{i}}{k W h_{e} A C_{t, i}}$

where "i" indicates the single measured data. The baseline is defined through a regression analysis between the amount of energy consumed for the production of compressed air and the production volumes of the industrial plants, according to the following relationship:

$k W h_{e} A C_{t, i}=\alpha+\beta * t_{i}$

In the above equation $\alpha$ and $\beta$ are the intercept and the slope of the best fitting line, calculated according to the followings:

$\alpha=k W h_{e} A C_{\text {average }}-b_{1} t_{\text {average }}$
$\beta=\frac{\Sigma\left(t_{i}-t_{\text {average }}\right)\left(k W h_{e} A C_{i}-k W h_{e} A C_{\text {average }}\right)}{\Sigma\left(t_{i}-t_{\text {average }}\right)^{2}}$

The strength of the correlation is evaluated using the $r^{2}$ and the p_value indexes [63].

Benchmarking results are illustrated using an assessment matrix, a scatterplot having the two variables used for the benchmarking analysis on its axes, and divided into quarters (illustrated in the Figure 2). The quarters are defined observing the fitting between the actual and the ideal cumulative frequency of the variables. Each point on the matrix is a different industrial plant.

According to the position of the points into the matrix, a different priority for possible energy-efficiency interventions can be identified, as follows. 
- In the up-right corner there are the most inefficient systems. The Efficiency Ratio for these systems is high and their energy efficiency is therefore very low. Efficiency interventions are of utmost priority, as it is possible to obtain very high energy savings.

- In the down-right corner there are quite inefficient plants. In this case the Efficiency Ratio is still very high but the value of the total consumption is a bit lower than in previous case. There is still the possibility to obtain high energy savings by imple menting energy efficiency improvement actions.

- In the up-left corner there are potentially critical systems. Their Efficiency Ratio is low but their consumption is high, so that it is worth to verify that their efficiency does not change over time.

- In the down-left corner there are the most efficient plants. In this case it is not usually worth to implement energy efficiency actions as all of these sites are already very efficient, and they can also be used as a reference to derive best practices to transfer to the other sites.

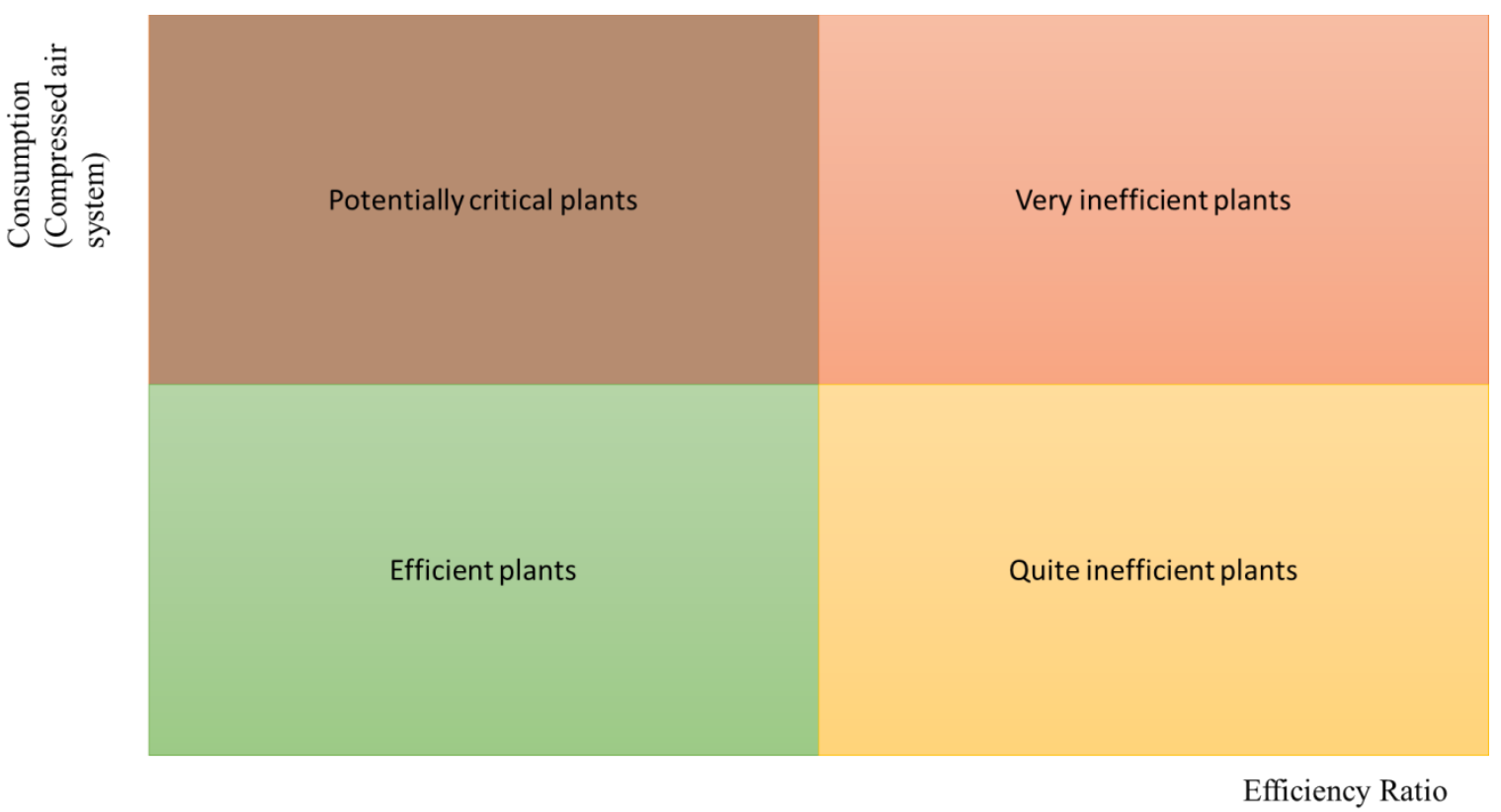

Fig. 2. Division of the assessment matrix into quarters

In addition, further information on CAS energy efficiency and support for companies' decision making can be drawn from this matrix. Those systems characterised by the same value of consumption and different efficiency ratio can be compared in order to identify and transfer best practices (these systems are most likely to have similar sizes). Systems characterised by the same value of efficiency ratio and different consumption can instead be compared as they should have similar operating condition, but clearly different levels of efficiency.

Thefore, the matrix can be also used to compare the efficiency of the own CAS with that of different business organizations in the same industrial sector (by positioning the own consumption and efficiency ratio values on the matrix). In addition, evolution of efficiency can also be monitored over time (by repositioning new values on the matrix). The matrix can therefore be a useful tool for researchers and policy makers in order to identify most (and less) efficient companies and organise knowledge-transfer activities. 


\section{Data analysis results}

In this section, the results of the data analysis are presented in details for the manufacture of basic metals in order to give a complete description of the presented methodology's application, while they are only briefly summarized for the other analysed sectors.

\subsection{In-depth analysis for manufacture of basic metals}

For the manufacture of basic metals, 223 questionnaires have been analysed. Of the corresponding 223 plants, 195 gave an estimation or a measure of the value of the amount of energy consumed for the production of compressed air. The highest percentage of questionnaires was returned by undertakings belonging to the casting of metal sub-sector (over 40\%) and the rest of them belongs to other 4 sub-sectors or did not declare it (over 20\%, see Figure 3).

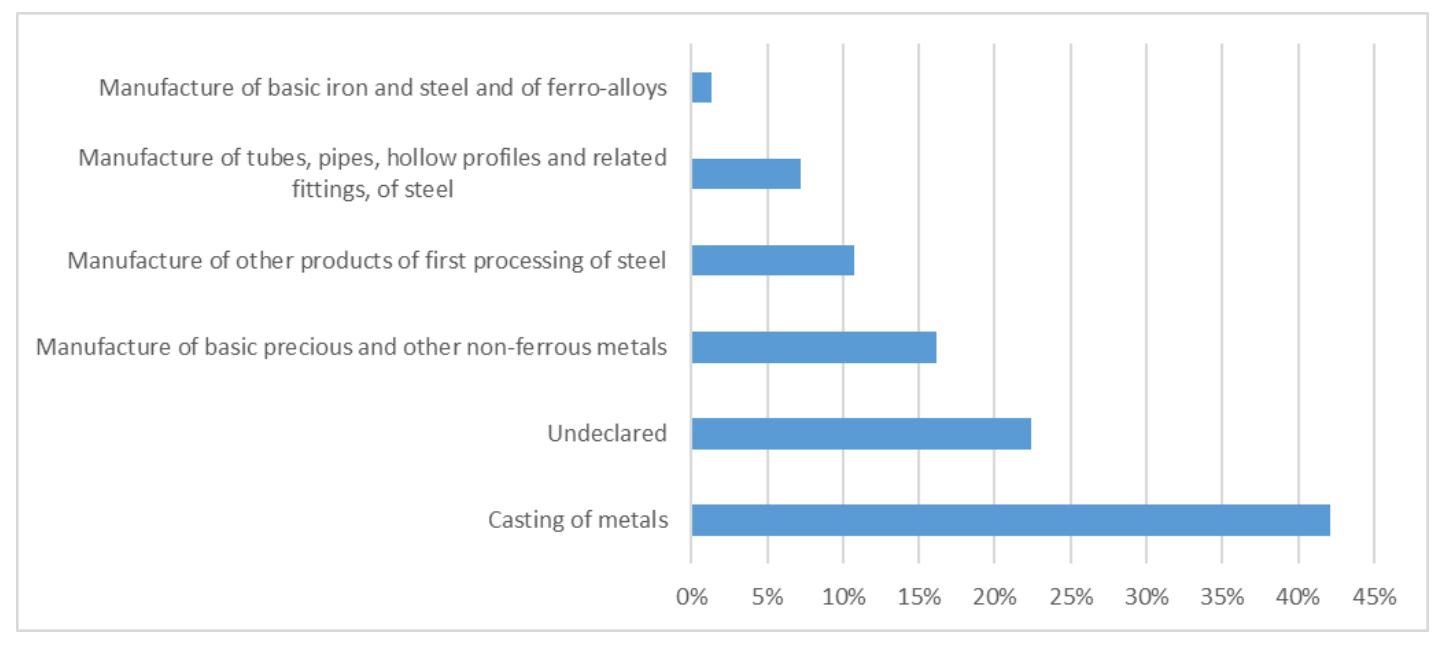

Fig. 3. Manufacturing of basic metals: percentage of questionnaires returned by undertakings belonging to different sub-sectors.

Figure 4 summarises the percent breakdown of responses to each question. The Figure highlights how continuous measures are generally used to estimate total electrical consumption (even if not in a very high percentage of analysed questionnaires), but rarely used to estimate the energy consumed for the production of compressed air. Furthermore, the majority of companies do not indicate any energy driver for the evaluation of the CAS's performance; in case they do, it is generally the amount of compressed air produced, but it is not clear how it is estimated. 


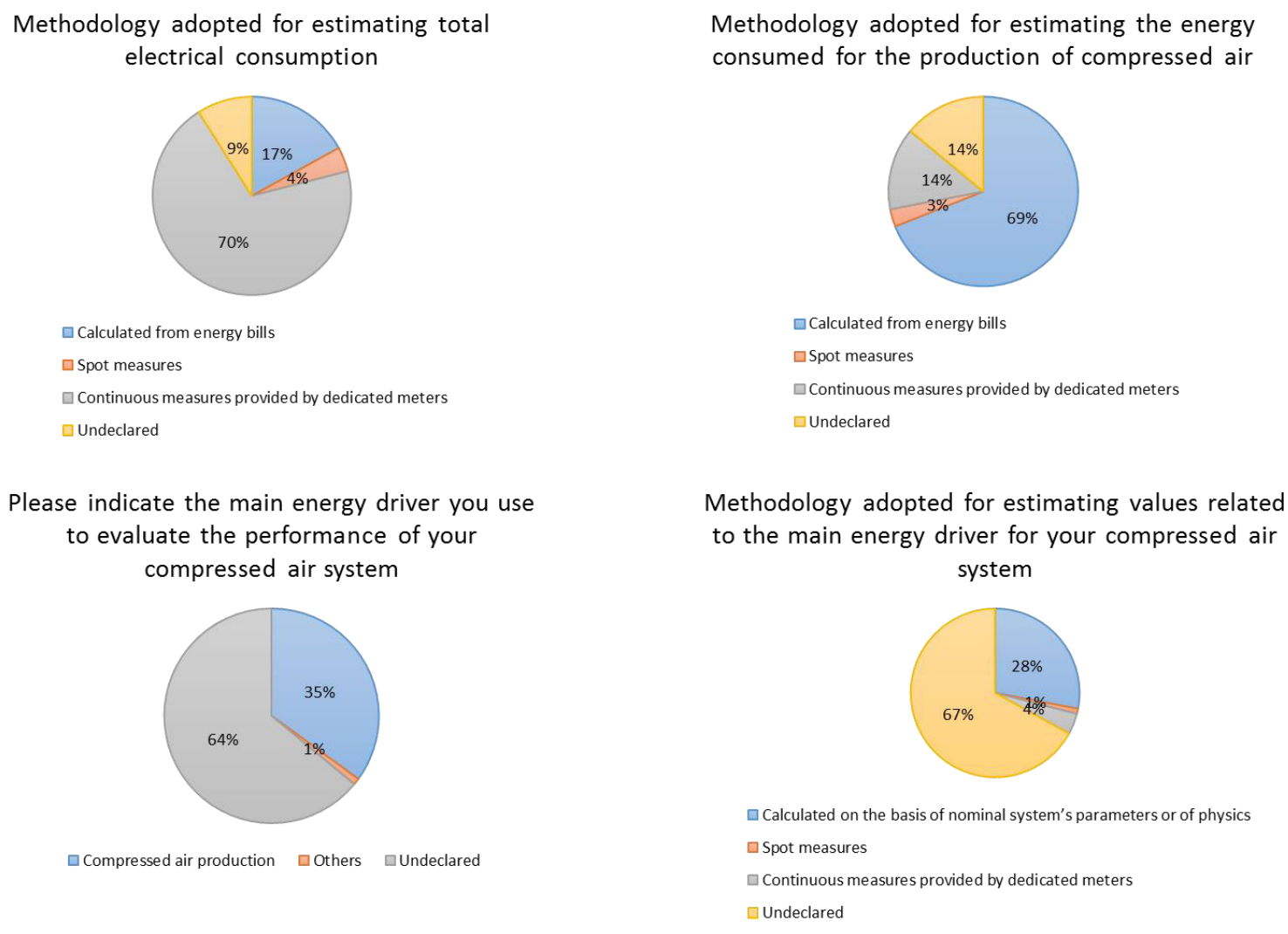

Fig. 4. Percentage breakdown of the four responses .

The plots of Figs. 5-7 report the results of the normality test and the descriptive statistics of main and derived variables for groups of data comprehending continuous measures. The same results for the whole sample are reported in figs. 8-10. Only plants measuring production volumes in weight have been considered, in order to analyse the ratio between the amount of energy consumed for the production of compressed air and the production volumes due to the fact that they are above $90 \%$ of the total. The ratio between the amount of energy consumed for the production of compressed air and the value of the main energy driver has not been analysed for each sector because this derived variable has been considered useful to analysis purpose only when both variables were measured (if not, one would have probably been derived from the other); thus, the amount of data available for each single industry was too narrow. 


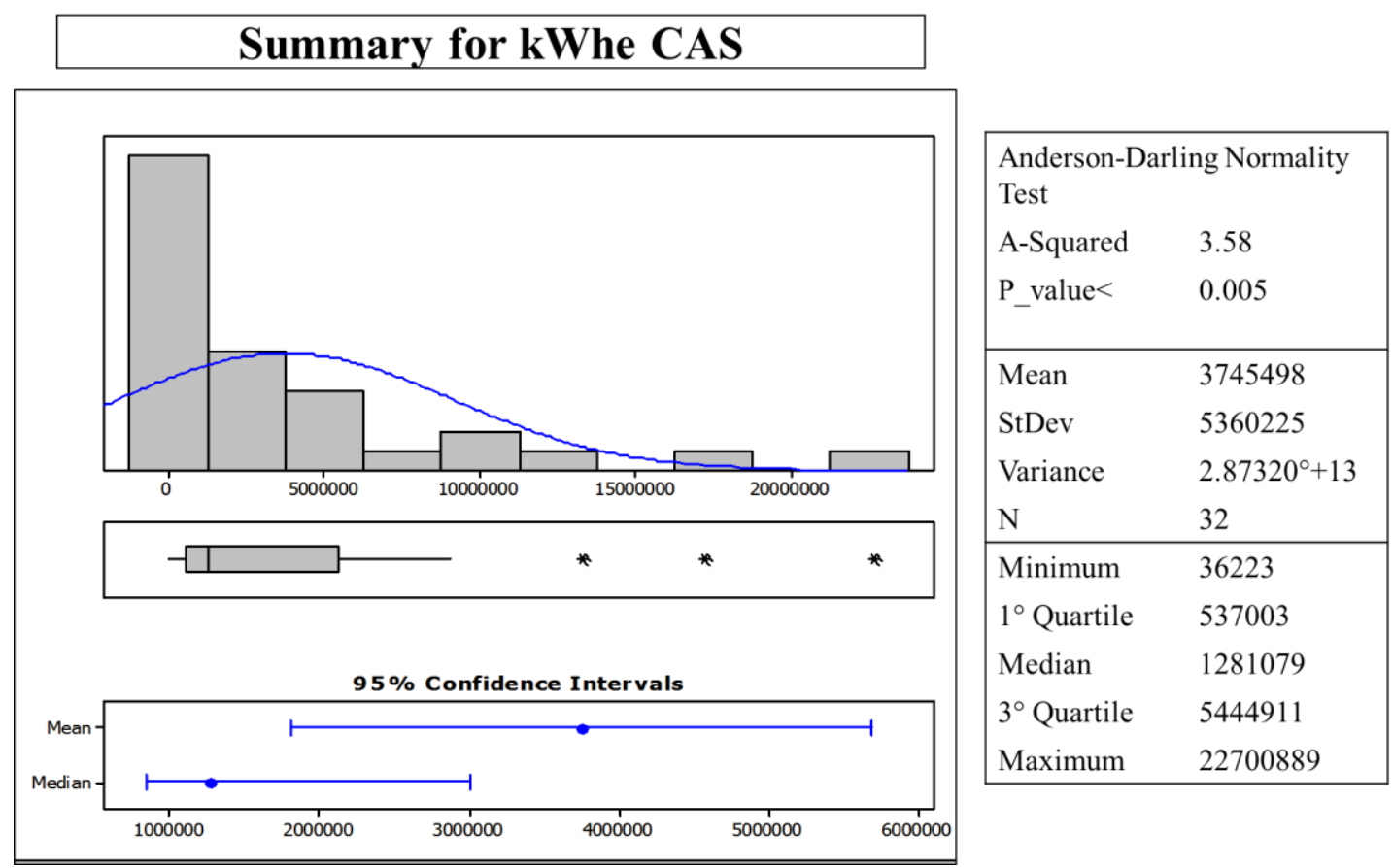

Fig. 5. Manufacturing of basic metals: normality test and descriptive statistics of kWhe CAS for groups of data comprehending continuous measures only.

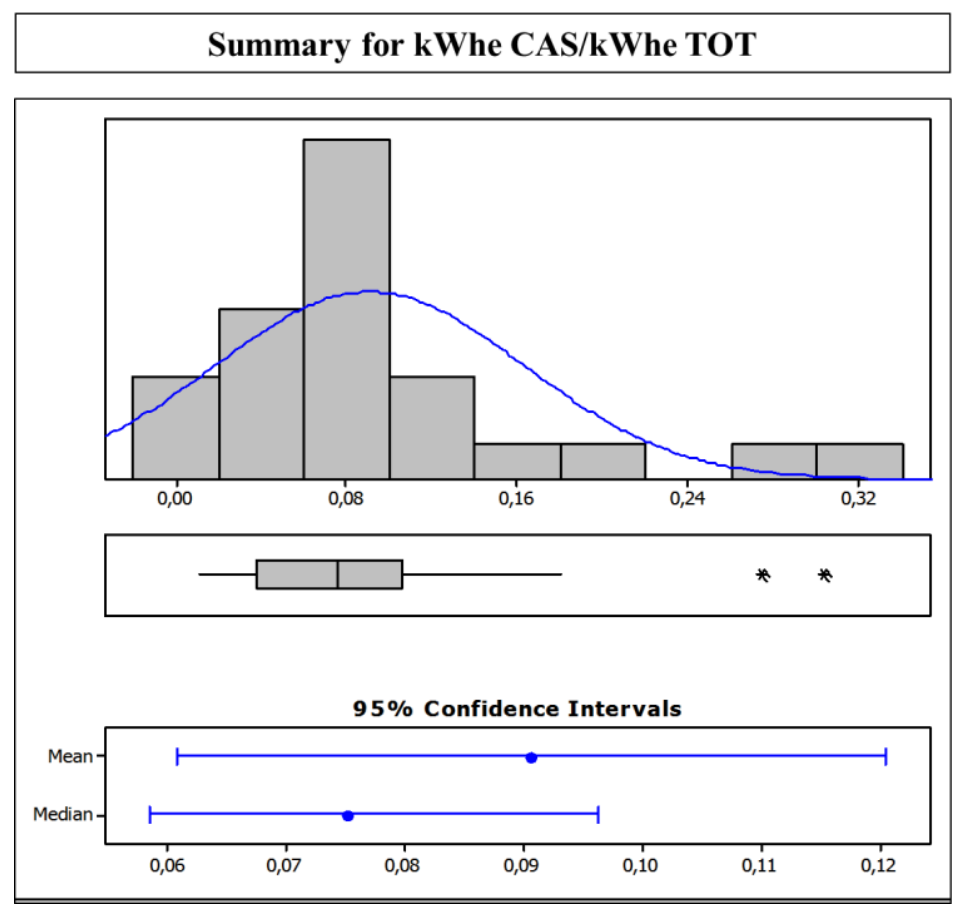

\begin{tabular}{|ll|}
\hline $\begin{array}{l}\text { Anderson-Darling Normality } \\
\text { Test } \\
\text { A-Squared }\end{array}$ & 1.52 \\
P_value $<$ & 0.005 \\
\hline Mean & 0.090615 \\
StDev & 0.072321 \\
Variance & 0.005230 \\
$\mathrm{~N}$ & 25 \\
\hline Minimum & 0.010237 \\
$1^{\circ}$ Quartile & 0.037904 \\
Median & 0.075276 \\
$3^{\circ}$ Quartile & 0.105878 \\
Maximum & 0.303860 \\
\hline
\end{tabular}

Fig. 6. Manufacturing of basic metals: normality test and descriptive statistics of kWhe CAS/kWhe TOT for groups of data comprehending continuous measures only. 


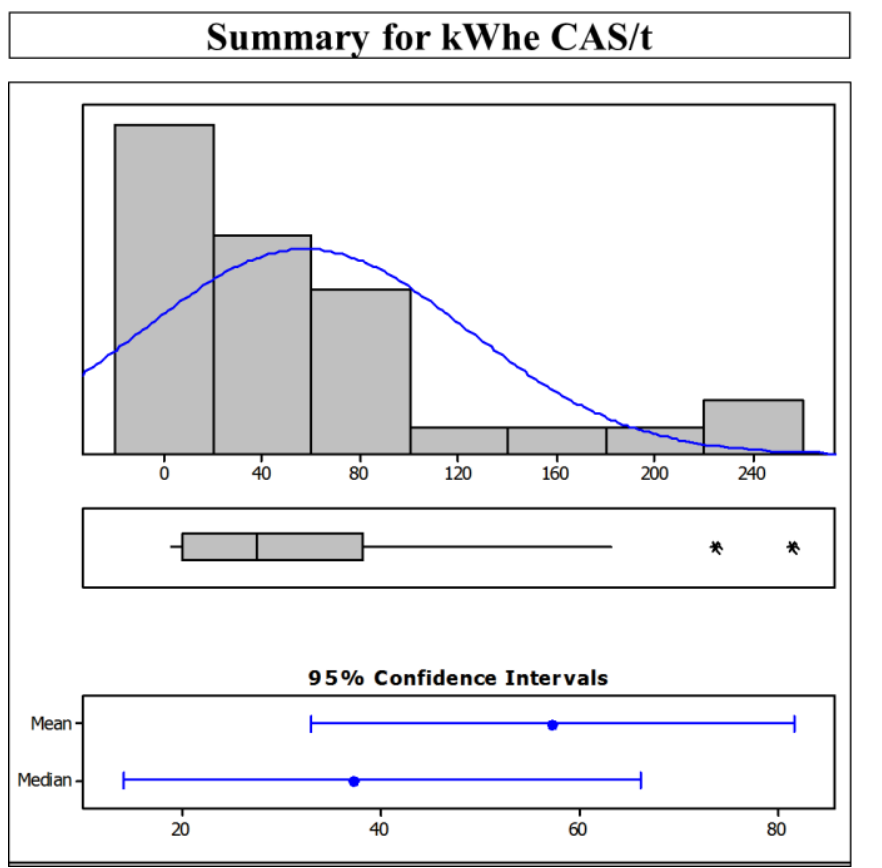

\begin{tabular}{|ll|}
\hline $\begin{array}{l}\text { Anderson-Darling Normality } \\
\text { Test } \\
\text { A-Squared }\end{array}$ & 2.23 \\
P_value $<$ & 0.005 \\
\hline Mean & 57.379 \\
StDev & 66.262 \\
Variance & 4390.615 \\
N & 31 \\
\hline Minimum & 2.168 \\
$1^{\circ}$ Quartile & 7.292 \\
Median & 37.353 \\
$3^{\circ}$ Quartile & 81.007 \\
Maximum & 255.452 \\
\hline
\end{tabular}

Fig. 7. Manufacturing of basic metals: normality test and descriptive statistics of kWhe CAS/t for groups of data comprehending continuous measures only.

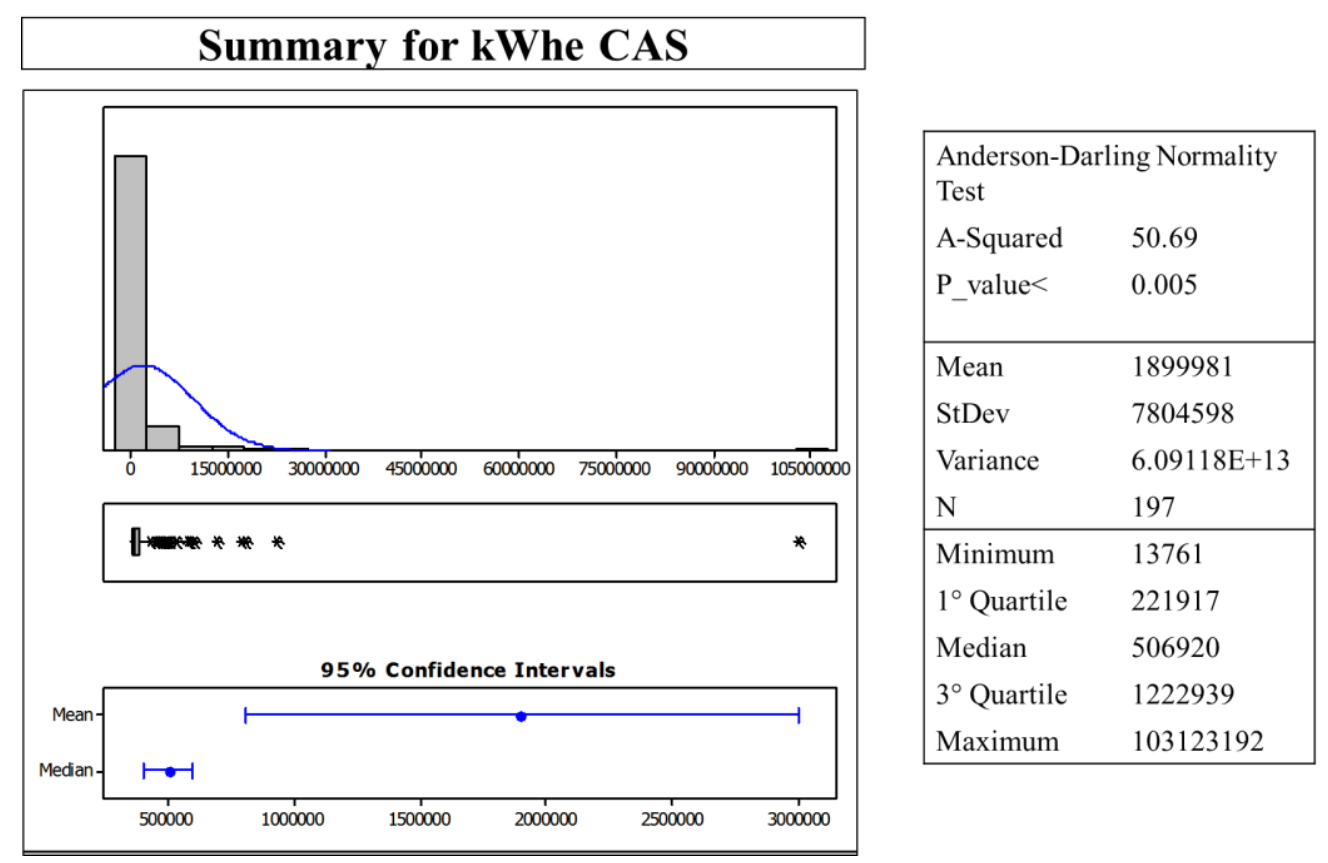

Fig. 8. Manufacturing of basic metals: normality test and descriptive statistics of kWhe CAS for all available data. 


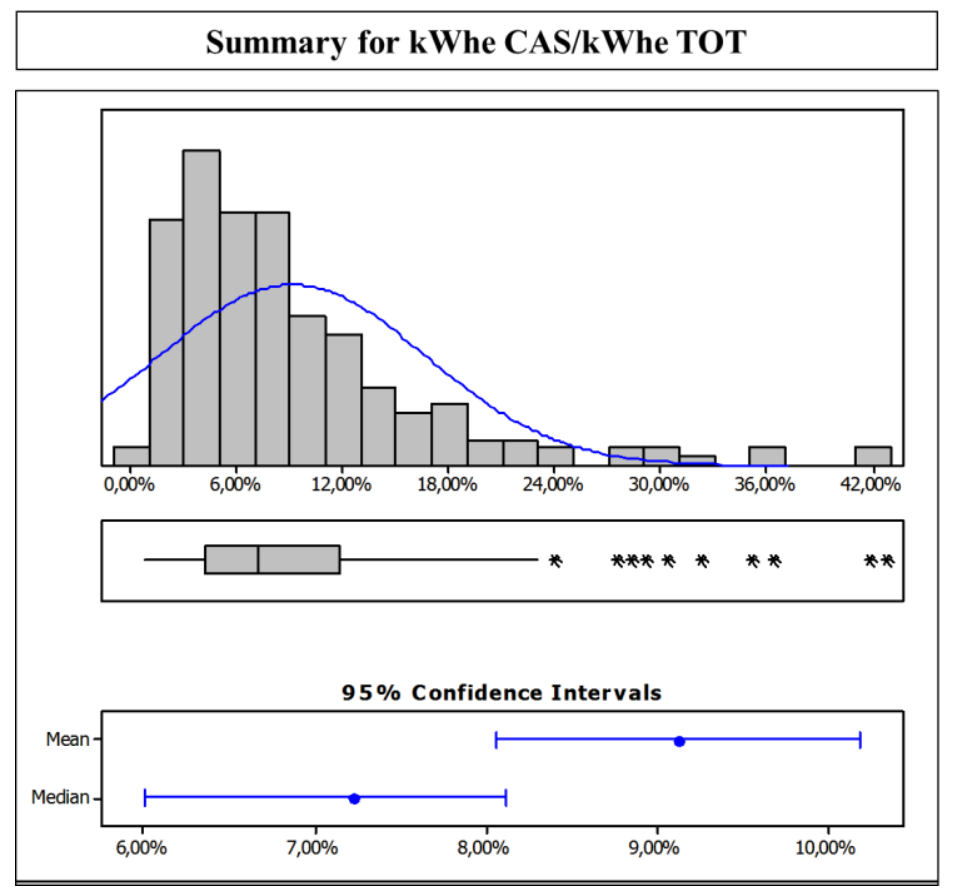

\begin{tabular}{|ll|}
\hline $\begin{array}{l}\text { Anderson-Darling Normality } \\
\text { Test } \\
\text { A-Squared }\end{array}$ & 9.27 \\
P_value $<$ & 0.005 \\
\hline Mean & 0.091210 \\
StDev & 0.075180 \\
Variance & 0.005652 \\
$\mathrm{~N}$ & 195 \\
\hline Minimum & 0.008125 \\
$1^{\circ}$ Quartile & 0.042023 \\
Median & 0.072231 \\
$3^{\circ}$ Quartile & 0.117998 \\
Maximum & 0.426587 \\
\hline
\end{tabular}

Fig. 9. Manufacturing of basic metals: normality test and descriptive statistics of kWhe CAS / kWhe TOT for all a vailable data.

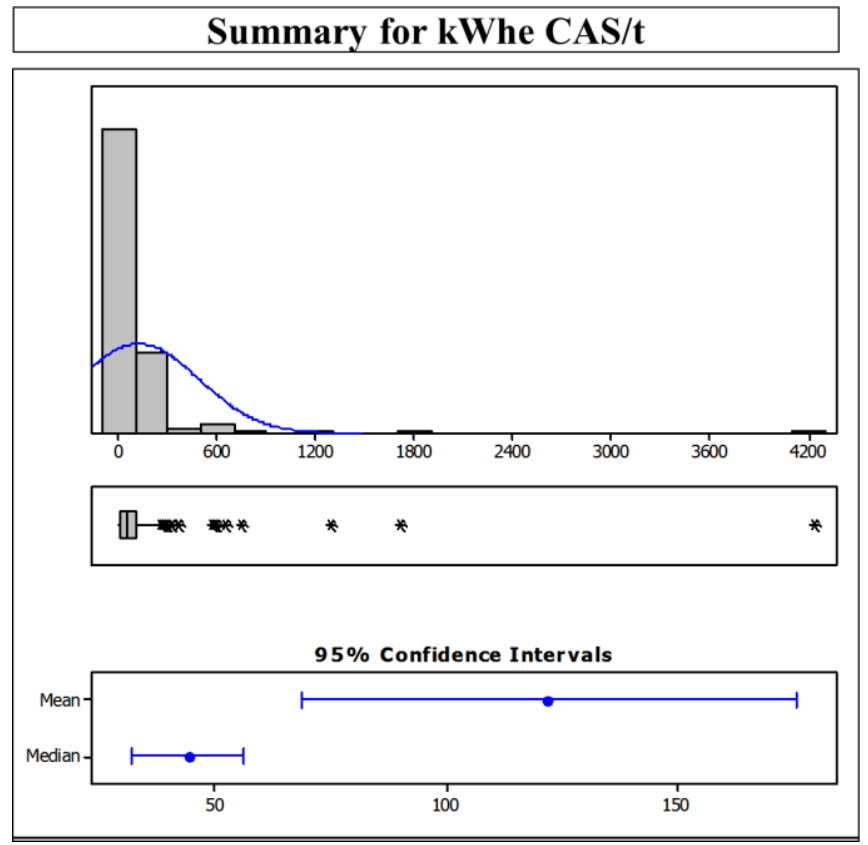

\begin{tabular}{|ll|}
\hline $\begin{array}{l}\text { Anderson-Darling Normality } \\
\text { Test } \\
\text { A-Squared }\end{array}$ & 38.03 \\
P_value $<$ & 0.005 \\
\hline Mean & 122.14 \\
StDev & 363.81 \\
Variance & 132357.78 \\
$\mathrm{~N}$ & 179 \\
\hline Minimum & 0.20 \\
$1^{\circ}$ Quartile & 12.70 \\
Median & 44.31 \\
$3^{\circ}$ Quartile & 100.47 \\
Maximum & 4231.71 \\
\hline
\end{tabular}

Fig. 10. Manufacturing of basic metals: normality test and descriptive statistics of $\mathrm{kWhe}$ CAS / $\mathrm{t}$ for all available data.

The mean value of the analysed variables and derived variables of plants belonging to different sub-sectors resulting from the Welch's One-Way ANOVA are not plotted for sake of brevity, but are in perfect agreement with the previous ones . Figure 11 depicts the assessment matrix for both the whole sample and the group of data comprehending continuous measures only. 

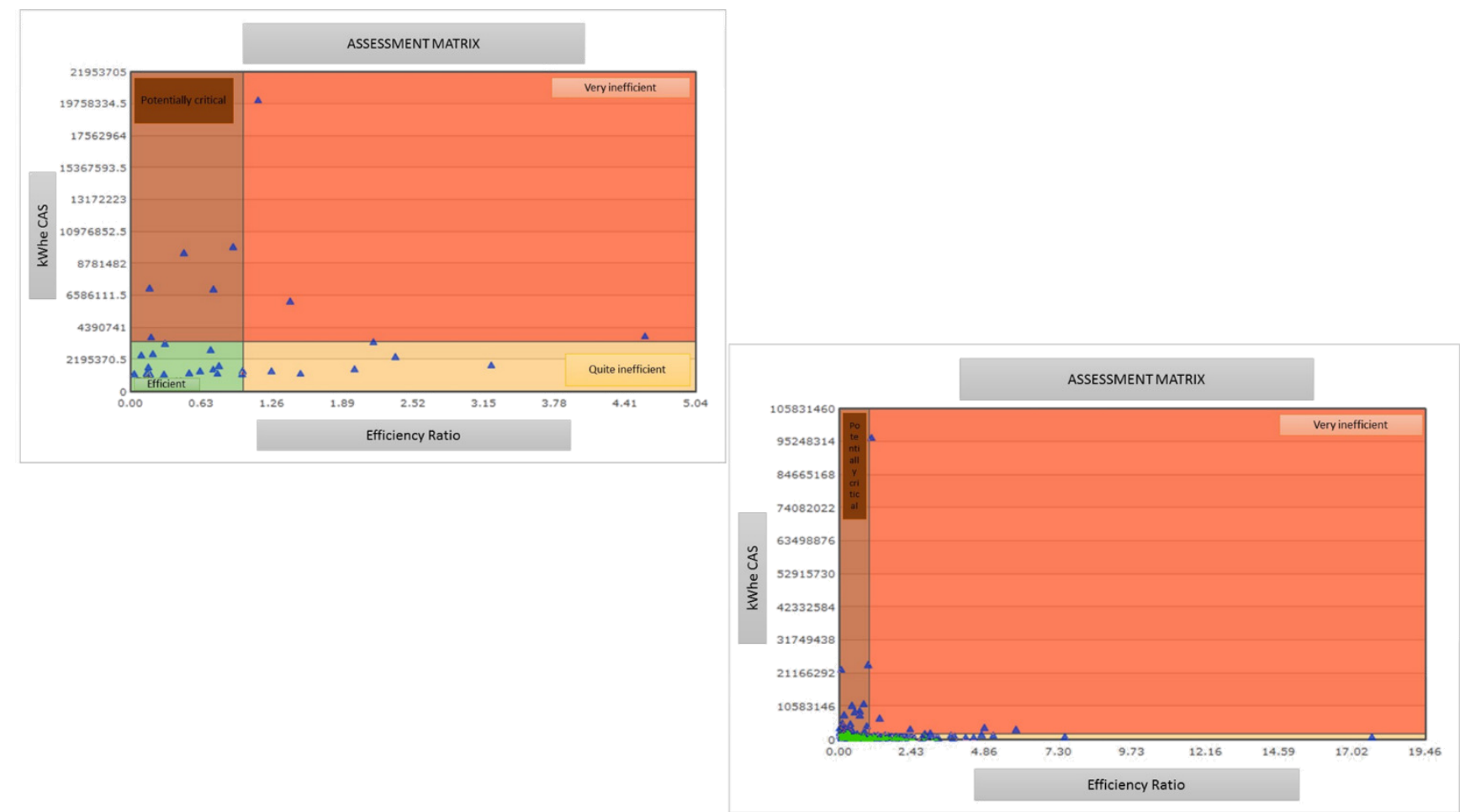

Fig. 11. Assessment matrix for the whole sample (on the left corner) and for the group of data comprehending continuous measures only (on the right corner).

Assessment matrixes for the subsectors are not reported, as there were not enough data or data were not good enough to obtain satisfactory results from the regression analysis.

\subsection{Summary of main results for all the analysed sectors}

Main results of data analysis are summarized in the matrix shown in Figure 7, which reports the various industries on columns and questions, variables and derived variables on rows. The green colour in the cells of the matrix means that values of answers, variables and derived variables highlight a satisfying amount of data collected or a relevant probability of profitably implement energy efficiency measures. Red colour means the opposite. Median values rather than means have been analysed, in order to obtain more reliable results, as several industries showed a relevant amount of outliers that have still got to be interpreted. The last row of the matrix reports the impact of the amount of energy consumed by CAS in each industry on the national industrial energy consumption (calculated according to data reported by [65]). 


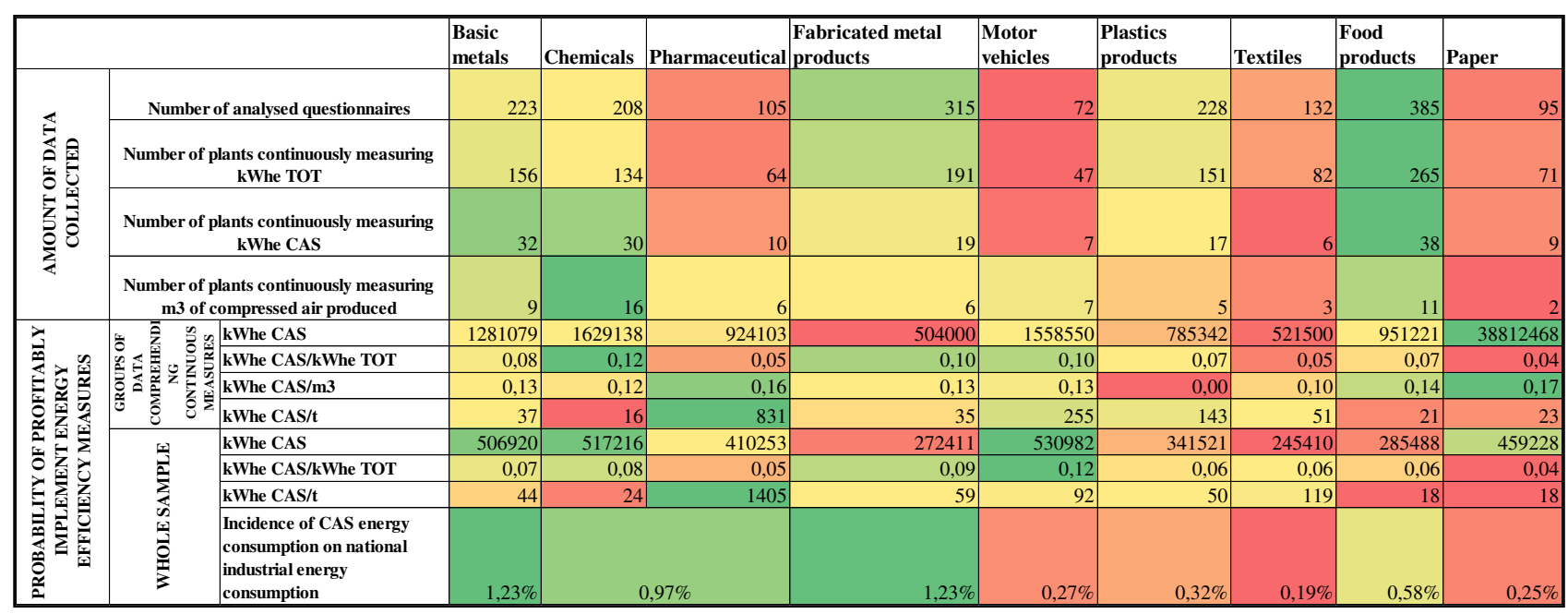

Fig. 12. Summary of the main results of the data analysis for all analyzed industries.

Figure 13 reports the results of the $\mathrm{kWhe} \mathrm{CAS} / \mathrm{m}^{3}$.

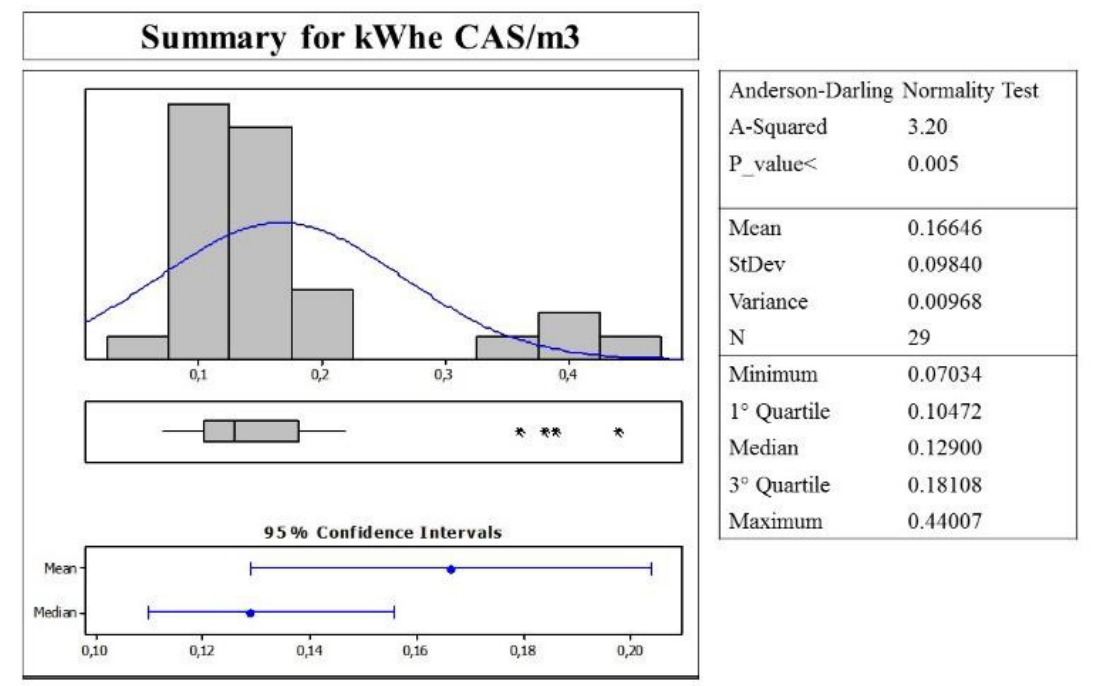

Fig. 13. Results of the analysis conducted on the ratio between the amount of energy consumed for the production of compressed air.

\section{Discussion}

Results from data analysis have led to the drawing of a first set of findings. First of all, the dramatically low percentage of plants measuring kWhe CAS as well as the amount of compressed air produced is an effective indicator of the still too little attention paid to energy management in Italian industrial plants. Despite the high energy cost related to compressed air production and the always more restrictive regulation, energy measuring, controlling, budgeting and forecasting are still rarely performed, not even in highly energy intensive systems. Therefore, the development of energy measuring systems should be considered as a priority over the next few years.

CAS appear to be a significant energy use in most industries, as the kWhe CAS/kWhe TOT derived variable ranges from $4 \%$ to $12 \%$, with a mean value across different industries of $7 \%$. They also cover a relevant percent of national industry consumption (i.e. a total of $5 \%$ considering all analysed industries). This is in line with values individuated in literature and reported in the introduction section, and being the first time such a value is calculated rather than estimated, it represents an encouraging start. 
The kWhe CAS/t derived variable seems to be a promising indicator for CAS energy efficiency within a single industry, as it appears to have a non-scattered distribution. On the other hand,it cannot definitely be used to compare different industries and this is probably due to the differences of the industrial processes required to produce different products.

Looking at the plots reported in Figs. 5-10, we observe that only few industrial plants show anomalous behaviours and are easily identifiable. Once the energy efficiency situation of these plants will be analysed, evaluating whether different performances are due to different systems' efficiency or to different operational parameters' settings, it will be possible to repeat the analysis on the same sample and verify the reliability of those values and distributions as benchmarks. In addition, plants showing anomalous behaviours are also identified by assessment matrixes (matrixes identify as anomalous the same plants appearing anomalous in the normality assess ment plots). These matrixes allow to clearly identify plants that need energy audits and energy efficiency measures, thus allowing to benchmark CAS in companies of the same sector and to prioritise interventions. Such matrixes can definitely be considered a very promising benchmarking tool.

Differences existing among subsectors are not significant for the sector considered in the present paper. This could be due to sector's or data characteristics, and causes should be further investigated.

The $\mathrm{kWhe} \mathrm{CAS} / \mathrm{m}^{3}$ is instead a good cross-sectorial indicator of the energy efficiency in the production of compressed air, but it does not allow measuring the energy efficiency in the consumption of such vector. An indicator such as the amount of compressed air used to produce a single ton of product would be useful, but the restricted number of plants measuring compressed air still does not allow its calculation. Anyway, Fig. 13 shows that the range of kWhe CAS $/ \mathrm{m}^{3}$ value is slightly above the one proposed by [6], which is probably due to the fact that the latter does not consider real use operating conditions. There is also a small number of industrial plants showing a much higher range. This is probably related to non-standard pressure requirements, although a deeper analysis is needed to confirm it.

\section{Conclusions and future developments}

First findings from an explorative study aimed at assessing CAS's energy efficiency and defining reliable and robust benchmarks have been presented. On the average, less than $20 \%$ of analyzed plants effectively measure kWhe CAS and about $7 \%$ of them measure the quantity of produced compressed air. CAS appear to be a significant energy use in most companies, covering on average the 7\% of kWhe TOT. Most promising benchmarking indicators and tools for both compressed air production and use and their calculation have been illustrated, along with their first application to a selected number of industries. In particular, the assessment matrix allows to easily and effectively individuate best performing CAS as well as systems needing improvement. By inputting their own data, companies can visualise their own CAS on the matrix and understand their performance in comparison with other companies from the same sector. Researchers/third parties can in addition use the matrix to enable sectorial and cross-sectorial knowledge transfer.

Through additional effort and data sets, the proposed methodology will allow to define cross-sectorial and industry-specific CAS energy efficiency benchmarks, enabling and enhancing a more efficient knowledge and best practices transfer among undertakings. Target companies will also be individuated to further test the use of the assessment matrix, its general applicability and the usefulness of results 
obtained by companies involved, This process will start off by considering industries showing relevant probability of profitably implement energy efficiency measures, so as to achieve the highest possible impact on national energy consumption in the short term.

\section{Acknowledgements}

This work is part of the Electrical System Research, implemented under Programme Agreements between the Italian Ministry for Economic Development and ENEA, CNR, and RSE S.p.A. The authors would like to thank all the companies that have kindly provided data and supported the project. Warm thanks also to Green Energy Plus S.r.l. that has provided useful feedbacks during the whole project.

\section{References}

[1] Directive 2012/27/EU of the European Parliament and of the Coucil of 25 October 2012 on energy efficiency; 2012; OJ L315/1.

[2] Yushchenko A, Patel MK. Contributing to a green energy economy? A macroeconomic analysis of an energy efficiency program operated by a Swiss utility. Appl Energ 2016;179:1304-1320.

[3] Lin B, Tan R. Ecological total-factor energy efficiency of China's energy intensive industries. Ecological Indicators 2016;70:480-497.

[4] Svensson A, Paramonova S. An analytical model for identifying and addressing energy efficiency improvement opportunities in industrial production systems - Model development and testing experiences from Sweden. J Clean Prod 2017;142:2407-2422.

[5] Zhou DQ, Wu F, Zhou X, Zhou P. Outpu-specific energy efficiency assessment: A data envelopment analysis approach..Appl Energ 2016;177:117-126.

[6] Introna V, Cesarotti V, Benedetti M, Biagiotti S, Rotunno R. Energy Management Maturity Model: an organizational tool to foster the continuous reduction of energy consumption in companies. J Clean Prod 2014;83:108-117.

[7] Benedetti M, Cesarotti V, Introna V, Serranti S. Energy consumption control automation using Artificial Neural Networks and adaptive algorithms: Proposal of a new methodology and case study. Appl Energ 2016;165:60-71.

[8] Radgen P, Blaustein E. Compressed Air Systems in the European Union: Energy, Emissions, Savings Potential and Policy Actions. 2001.

[9] Phelan P, Chau D, Sarac H., Kaya D. Energy conservation in compressed-air systems. Int J Energ Res 2002;26:837-849.

[10] Saidur R, Rahim N, Hasanuzzaman M. A review on compressed-air energy use and energy savings. Renew Sust Energ Rev 2010;14:1135-1153.

[11] Dindorf R. Estimating Potential Energy Savings in Compressed Air Systems. Procedia Engineering 2012;39:204-211.

[12] Legislative Decree 102 [Republic of Italy], 4 July 2014, available at: http://www.gazzettaufficiale.it/eli/id/2014/07/18/14G00113/sg [accessed 29 May 2016].

[13] European Commission. The new SME definition, User guide and model declaration. Enterprise and industry publications; 2005.

[14] European Commission. Reference document on Best Available Techniques for Energy Efficiency. 2009.

[15] Anglani N, Mura P. Optimization opportunities in compressed air production, distribution and use of compressed air in most relevant sectors (Opportunità di ottimizzazione dei consumi nella produzione, distribuzione, utilizzo dell'aria compressa nei settori industriali più sensibili). ENEA, 2010.

[16] U.S. Department of Energy, Energy Efficiency and Renewable Energy. Compressed Air Challenge. Improving compressed air system performance, a sourcebook for industry. 2003.

[17] Li MJ, Tao WQ. Review of methodologies and policies for evaluation of energy efficiency in high energy-consuming industry. Appl Energ 2017; 187:203-2015.

[18] Ke J, Price L, McNeil M, Khanna NZ, Zhou N. Analysis and practices of energy benchmarking for industry from the perspective of systems engineering. Energ 2013;54:32-44.

[19] Festel G, Wurmseher M. Benchmarking of energy and utility infrastructures in industrial parks. J Clean Prod 2014;70:15-26.

[20] Chung W. Review of building energy-use performance benchmarking methodologies. Appl Energ 2011;88:1470-1479.

[21]Lee WS, Lee KP. Benchmarking the performance of building Energy management using data envelopment analysis. Appl Therm Eng 2009;29:32693273.

[22] Wong LT, Mui KW, Law LY. An Energy consumption benchmarking system for residential buildings in Hong Kong. Build Serv Eng Res Technol 2009;30:135-142.

[23] Wu XC, Priya darsini R, Eang LS. Benchmarking energy use and green-house gas emissions in Singapore's hotel industry. Energ Pol 2010;38:45204527.

[24] Wang N, Wen Z, Liu M, Guo J. Constructing an energy efficiency benchmarking system for coal production. Appl Energ 2016;169:301-308.

[25] Li Z, Han Y, Xu P. Methods for benchmarking building energy consumption against its past or intended performance: an overview. Appl ENerg 2014;124:325-334.

[26] Zhao H, Magoules F. A review on the prediction of building energy consumption. Renew Sust Energ Rev 2012;16(6):3586-3592.

[27] Perez-Lombardi L, Ortiz J, Gonzalez R, Maestre IR. A review of benchmarking rating and labelling concepts within the framework of building energy certification schemes. Energ Build 2009;41(3):272-278.

[28] Ahn J, Cho S, Chung DH. Development of a statistical analysis model to benchmark the energy use intensity of subway stations. Appl Energ 2016;179:488-496.

[29] Longo S, d'Antoni BM, Bongards M, Chaparro A, Cronrath A, Fatone F, Lema JM, Mauricio-Iglesias M, Soares A, Hospido A. Monitoring and diagnosis of energy consumption in wastewater treatment plants. A state of the art and proposals for improvement. Appl Energ 2016;179:1251-1268.

[30] Kalaiselvan ASV, Subramaniam U, Shanmugam P, Hanigovszki N. A comprehensive review on energy efficiency enhancement initiatives in centrifugal pumping system. Appl Energ 2016;181:495-513.

[31] Mui KW, Wong LT, Law LW. An energy benchmarking model for ventilation system of air conditioned offices in subtropical climates. Appl Energ 2007;84:89-98.

[32] Lindberg CF, Tan ST, Yan JY, Starfelt F. Key performance indicators improve industrial performance. Energ Proc 2015;75:1785-1790.

[33] Chung W, Hui YV, Miu Lam Y. Benchmarking the energy efficiency of commercial buildings. Appl Energ 2006;83:1-14.

[34] Sahoo LK, Bandyopadhyay S, Banerjee R. Benchmarking energy consumption for dump trucks in mines. Appl Energ 2014;113:1382-1396.

[35] Omid M, Ghojabeige F, Delshod M, Ahmadi H. Energy use pattern and benchmarking of selected green houses in Iran using data envelopment analysis. Energ Convers Manage 2011;52(1):153-162.

[36] Chauhan NS, Mohapatra PKJ, Pandey KP. Improving energy productivity in paddy production through benchmarking: an application of data envelopment analysis. Energ Convers Manage 2006;47:1063-1085. 
[37] Boyd G, Dutrow E, Tunnessen W. The evolution of energy star energy performance indicator for benchmarking industrial plant energy use. J Clean Prod 2008;16:709-715

[38] Sardeshpande V, Gaitonde UN, Banerjee R. Model based energy benchmarking for glass furnace. Energ Convers Manage 2007;48:2718-2738.

[39] Holiastos K, Manousiouthakis V. The minimum hot/cold/electric cost for heat exchange networks. Comput Chem Eng 2002;26:3-16.

[40] Grabowski M, Klemes J, Urbaniec K, Vaccari G, Zhu XV. Minimum energy consumption in sugar production by cooling crystallization of concentrated raw juice. Appl Therm Eng 2002;26:3-16.

[41] Yin Y, Zheng B, Yang C, Zhang X. A proposed compressed air drying method using pressurized liquid desiccant and experimental verification. Appl Energ 2015;141:80-89.

[42] Budt M, Wolf D, Span R, Yan J. A review on compressed air energy storage: Basic principles, past milestones and recent developments. Appl Energ 2016;170:250-268. [43] Neale JR, Kamp PJJ. Compressed air system best practice programmes: What needs to change to secure long-term energy savings for New Zealand? Energ Pol 2009;37:3400-3408.

[44] Saidur R, Mekhilef S. Energy use, energy savings and emission analysis in the Malaysian rubber producing industries. Appl Energ 2010;87:2746-2758. [45] Thollander P, Karlsson M, Soderstrom M, Creutz D. Reducing industrial energy costs through energy-efficiency measures in a liberalized European electricity market: case study of a Swedish iron foundry. Appl Energ 2005;81:115-126.

[46] Spiering T, Kohlitz S, Sundmaeker H, Herrmann C. Energy efficiency benchmarking for injection moulding processes. Robotics and ComputerIntegrated Manuf 2015;36:45-59.

[47] Facci, A. L., Sánchez, D., Jannelli, E.,, Ubertini, S. Trigenerative micro compressed air energy storage: Concept and thermodynamic assessment. Appl Energ 2015, 158, 243-254.

[48] McKane A, Medaris B. The Compressed Air Challenge: Making a Difference for US Industry. In Energy Efficiency in Motor Driven Systems. Springer; 2003.

[49] Zhang T, Rangarajan A, Dornfeld D, Ziemba B, Whitbeck R, Yuan CY. A decision-based analysis of compressed air usage patterns in automotive manufacturing. J Manuf Syst 2006;25(4):293-300.

[50] Sustainability Victoria. Energy Efficiency Best Practice Guide Compressed air Systems. 2009.

[51] Abdelaziz EA, Saidur R, Mekhilef S. A review on energy saving strategies in industrial sector. Renew Sust Energ Rev 2011;15:150-168.

[52] Mousavi S, Kara S, Kornfeld B. Energy Efficiency of Compressed Air Systems. Procedia CIRP 2014;15:313-318.

[53] Vittorini D, Cipollone R. Energy saving potential in existing industrial compressors. Energ 2016;102:502-515.

[54] Office of Industrial Technologies. Inappropriate Uses of Compressed Air. 1998

[55] Hanlon P. Compressor handbook. McGrawHill Professional, 2000, 2001.

[56] CEATI. Compressed Air Energy Efficiency Reference Guide. 2007.

[57] Carbon Trust. Compressed Air. 2012.

[58] Compressed Air and Gas Institute. Compressed Air and Gas Handbook. Sixth edit ed., 2012.

[59] Atlas Copco. Compressed Air Manual. 8th ed., 2015.

[60] U.S. Environmental Protection Agency. Wise rules for industrial efficiency, a toolkit for estimating energy savings and greenhouse gas emissions reductions, 1998

[61] EUROSTAT. NACE Rev.2, Statistical Classification of economic activities in the European Community. 2008

[62] Liao H, Du YF, Huang Z, Wei YM. Measuring energy economic efficiency: A mathematical programming approach. Appl Energ 2016;179:479-487.

[63] Anderson T W, Darling DA. Asymptotic theory of certain "goodness-of-fit" criteria based on stochastic processes. Ann Math Stat 1952;23:193-212.

[64] Welch BL. The generalization of "Student's" problem when several different population variances are involved. Biometrika 1947;34(1-2):28-35.

[65] TERNA. Electrical consumption in Italy, available at http://www.terna.it/it-

it/sistemaelettrico/statisticheeprevisioni/consumienergiaelettricapersettoremerceologico.aspx [accessed 29 May 2016]. 